\title{
A comparison between the combined effect of calcium carbonate with sucroferric oxyhydroxide and other phosphate binders: an in vitro and in vivo experimental study
}

Atsushi Yaguchi ${ }^{*}$, Kenji Akahane, Kumi Tsuchioka, Saori Yonekubo, Shota Yamamoto, Yasuaki Tamai, Satoshi Tatemichi and Hiroo Takeda

\begin{abstract}
Background: Approximately 30\% of patients on dialysis received combination therapy for their phosphate binder prescription; however, few studies for combined effects of phosphate binders are reported. For the purpose of evaluating the efficacy of combination therapy, we compared the efficacy of sucroferric oxyhydroxide (PA21) combined with calcium carbonate with that of lanthanum carbonate hydrate, sevelamer hydrochloride, and ferric citrate hydrate combined with calcium carbonate.

Methods: For in vitro studies, calcium carbonate and the other phosphate binders alone or in combination were stirred in phosphate solution at pH 2-8 for $2 \mathrm{~h}$. After centrifuging the suspension, the phosphorus level in the supernatant was determined. For in vivo studies, rats were orally administered calcium carbonate and the other phosphate binders (except for sevelamer hydrochloride) alone or in combination, followed by oral administration of phosphate solution adjusted to $\mathrm{pH} 2$ or 7 . Serum samples were collected from the rats at predetermined timepoints and the serum phosphorus levels were determined and analyzed using a two-way analysis of variance.

Results: In the in vitro study, the measured phosphate-binding capacity of combining sevelamer hydrochloride, PA21, and lanthanum carbonate hydrate with calcium carbonate was approximately equal to or greater than the theoretical values under most conditions. Furthermore, these combined effects were insensitive to $\mathrm{pH}$ in that order. The measured phosphate-binding capacity of ferric citrate hydrate combined with calcium carbonate was smaller than the theoretical values, and the combination did not exhibit efficacy under any of the tested conditions. In the in vivo study, the combined effect of PA21 and calcium carbonate at both pH values and that of lanthanum carbonate hydrate and calcium carbonate at $\mathrm{pH} 2$ were additive. In contrast, the combined effect of lanthanum carbonate hydrate and calcium carbonate at $\mathrm{pH} 7$ and that of ferric citrate hydrate and calcium carbonate at pH 2 were antagonistic.

Conclusions: These results suggest that coadministration of PA21 and calcium carbonate showed good and relatively stable efficacy throughout the range of the gastrointestinal $\mathrm{pH}$ and that combining lanthanum carbonate hydrate and ferric citrate hydrate with calcium carbonate may not produce the expected efficacy under certain conditions.
\end{abstract}

Keywords: Hyperphosphatemia, Phosphate binders, Sucroferric oxyhydroxide, Calcium carbonate, Combined effects, Combination therapy

\footnotetext{
* Correspondence: atsushi_yaguchi@pharm.kissei.co.jp

Pharmacology Research Group, Pharmacology and Pharmacokinetics

Research Laboratory, R\&D, Kissei Pharmaceutical Co., Ltd., 4365-1

Kashiwabara, Hotaka, Azumino, Nagano 399-8304, Japan
}

(c) The Author(s). 2019 Open Access This article is distributed under the terms of the Creative Commons Attribution 4.0 International License (http://creativecommons.org/licenses/by/4.0/), which permits unrestricted use, distribution, and

reproduction in any medium, provided you give appropriate credit to the original author(s) and the source, provide a link to the Creative Commons license, and indicate if changes were made. The Creative Commons Public Domain Dedication waiver (http://creativecommons.org/publicdomain/zero/1.0/) applies to the data made available in this article, unless otherwise stated. 


\section{Background}

In patients with end-stage kidney disease, renal function is reduced along with phosphorus excretion from the kidney, resulting in the accumulation of absorbed dietary phosphorus in the body and hyperphosphatemia [1-3]. Chronic kidney disease (CKD) is accompanied by systemic abnormalities such as laboratory test abnormalities, ectopic calcification, and bone disorder, which are collectively called CKD-mineral and bone disorder (CKD-MBD) and affect prognosis [4]. Serum phosphorus level has been reported to contribute the most to mortality among values of laboratory examination (serum phosphorus, calcium, and parathyroid hormone levels) recommended to be controlled within reference values for the treatment of CKD-MBD. Therefore, appropriate control of serum phosphorus level is required in the treatment of CKD-MBD $[5,6]$. In clinical practice, restriction of dietary phosphate intake and phosphorus excretion with dialysis are performed to control serum phosphorus levels of patients on dialysis; however, these measures alone are not sufficient and phosphorus absorption from the gastrointestinal tract needs to be suppressed using oral phosphate binders [7].

Currently, oral phosphate binders such as calcium carbonate, sevelamer hydrochloride, lanthanum carbonate hydrate, ferric citrate hydrate, and sucroferric oxyhydroxide are used to treat hyperphosphatemia in Japan. Among these, calcium carbonate is universally used because of usage experience, efficacy, and much lower cost. However, the calcium carbonate dosage is restricted because calcium overload promotes coronary arterial and ectopic calcification and is associated with mortality [8-11]. As a countermeasure for these issues, calcium carbonate has been used in combination with other phosphate binders.

We previously reported that the effect of different $\mathrm{pH}$ values on the phosphate-binding capacity varied among phosphate binders [12]. In that study, calcium carbonate was one of the drugs with a phosphate-binding capacity that was susceptible to $\mathrm{pH}$. Furthermore, since calcium carbonate is an alkaline drug with the associated physical property, the $\mathrm{pH}$ of the gastrointestinal tract may change after administration. This suggests that changes in the $\mathrm{pH}$ of the gastrointestinal tract due to calcium carbonate could affect the efficacy of other phosphate binders when they are coadministered with calcium carbonate. Additionally, other phosphate binders such as ferric citrate hydrate are acidic drugs, and, in contrast to the above, they might inhibit the efficacy of calcium carbonate.

Several studies have compared the phosphate-binding capacity of phosphate binders to date [12-14]. Furthermore, Cannata-Andía et al. have reported that the combined therapies with calcium-containing phosphate binders, sevelamer and lanthanum carbonate showed a beneficial association with survival in clinical practice
[15]; however, there have been few detailed comparisons of phosphate-binding capacity in the combined therapies including new phosphate binders such as sucroferric oxyhydroxide. Therefore, for the purpose of evaluating the efficacy of combination therapy for phosphate binders, we examined the combined effect of sucroferric oxyhydroxide (PA21) and calcium carbonate in vitro and in vivo, and compared it with that of calcium carbonate in combination with other phosphate binders (lanthanum carbonate hydrate, sevelamer hydrochloride, and ferric citrate hydrate).

\section{Methods \\ Drugs used}

PA21 (Vifor Pharma, Glattbrugg, Switzerland), lanthanum carbonate hydrate (Alfa Aesar, Lancashire, UK), sevelamer hydrochloride (AK Scientific, Inc., Union City, CA, USA), calcium carbonate (FUJIFILM Wako Pure Chemical Corporation, Osaka, Japan), and ferric citrate hydrate (Nacalai Tesque, Inc., Kyoto, Japan) were used for the experiments. For the in vivo studies, each investigational drug was dissolved or suspended in $0.5 \%(\mathrm{w} / \mathrm{v})$ methylcellulose (MC) solution (FUJIFILM Wako Pure Chemical Corporation). After phosphate (FUJIFILM Wako Pure Chemical Corporation), disodium hydrogen phosphate dodecahydrate (FUJIFILM Wako Pure Chemical Corporation), and sodium dihydrogen phosphate dihydrate (FUJIFILM Wako Pure Chemical Corporation) were diluted or dissolved in distilled water, the resulting phosphate solution was mixed and adjusted to $\mathrm{pH} 2,3$, $4,5,6,7$, or 8 [16], simulating the conditions in the digestive tract.

\section{Animals used}

Male Sprague-Dawley (SD) rats (Charles River Laboratories Japan, Inc., Yokohama, Japan), 6-7 weeks of age and $140-250 \mathrm{~g}$ at arrival, were housed in groups of 3-5 per cage, and reared under constant temperature (20$26^{\circ} \mathrm{C}$ ), humidity $(30-70 \%)$, and a $12 \mathrm{~h}$ light cycle (lights on at $8 \mathrm{AM}$, and off at $8 \mathrm{PM})$. All animals were provided with free access to water and a diet containing $1.08 \%$ (0.98-1.17\%) phosphorus and 25.5\% (24.6-26.3\%) crude protein (CE-2 pellet, CLEA Japan, Inc., Tokyo, Japan). All animal experiments were performed in accordance with the guidelines approved by the Laboratory Animal Committee of Kissei Pharmaceutical Co., Ltd., which conform to the current Japanese laws.

\section{In vitro phosphate-binding capacity Phosphate-binding capacity of various phosphate binders at $\mathrm{pH}$ 2-8}

In $40 \mathrm{~mL}$ phosphate solution $(20 \mathrm{mM}=1899 \mathrm{mg}$ phosphate $/ \mathrm{L}=619 \mathrm{mg}$ phosphorus/L), $200 \mathrm{mg}$ PA21, lanthanum carbonate hydrate, sevelamer hydrochloride, 
calcium carbonate, or ferric citrate hydrate was suspended, and the resulting suspensions were stirred $\left(37^{\circ} \mathrm{C}, 2 \mathrm{~h}\right)$. The suspension was pelleted by centrifugation $\left(37^{\circ} \mathrm{C}\right.$, $2330 \times g, 5 \mathrm{~min}$ ) after stirring, and the supernatant was collected. The phosphorus level in the supernatant was measured using spectrophotometry (SpectraMax, Molecular Devices Japan, K.K., Tokyo, Japan) by the molybdenum blue method (Phosphor C-Test Wako, FUJIFILM Wako Pure Chemical Corporation). The quantities of phosphate adsorbed onto $1 \mathrm{~g}$ of the ingredients in the investigational drug were determined as the phosphate-binding capacity of the drug. As shown in Table 1, the ingredients in PA21, lanthanum carbonate hydrate, calcium carbonate, and ferric citrate hydrate were regarded as the respective metals and that in sevelamer hydrochloride was regarded as sevelamer in this study.

\section{Phosphate-binding capacity of calcium carbonate coadministered with each phosphate binder at pH 2-8} In $40 \mathrm{~mL}$ phosphate solution $(20 \mathrm{mM}), 100 \mathrm{mg}$ calcium carbonate and $100 \mathrm{mg}$ PA21, lanthanum carbonate hydrate, sevelamer hydrochloride, or ferric citrate hydrate were suspended. The resulting suspensions were stirred $\left(37^{\circ} \mathrm{C}, 2 \mathrm{~h}\right)$, pelleted by centrifugation $\left(37^{\circ} \mathrm{C}, 2330 \times g, 5 \mathrm{~min}\right)$ after stirring, and the supernatant was collected. The phosphorus level in the supernatant was measured using Phosphor CTest Wako and SpectraMax in accordance with the method specified in the previous section, and the quantities of phosphate adsorbed onto $1 \mathrm{~g}$ of the total ingredients (the mixture of two ingredients, e.g., iron and calcium for PA21 and calcium carbonate used together) of the whole investigational drug for combination use was determined as the measured phosphate-binding capacity in combination use. Furthermore, the quantities of phosphate adsorbed in single drug, which were obtained in the previous section, and the composition (\%) of each ingredient of the whole investigational drug in combination use (Table 2) were used to calculate the theoretical phosphate-binding capacity following combined use, according to the following formula.

$$
\text { Theoretical value }=\mathrm{Q}_{\mathrm{CC}} \times \mathrm{C}_{\mathrm{CC}}+\mathrm{Q}_{\mathrm{PB}} \times \mathrm{C}_{\mathrm{PB}}
$$

QCC: The quantity of phosphate adsorbed onto $1 \mathrm{~g}$ of the ingredient of calcium carbonate (calcium).
Qрв: The quantity of phosphate adsorbed onto $1 \mathrm{~g}$ of the ingredient of each phosphate binder (iron, lanthanum, or sevelamer,).

$\mathrm{C}_{\mathrm{CC}}$ : The composition (\%) of the ingredient of calcium carbonate (calcium) to the ingredients of the whole investigational drug in combination use.

$\mathrm{C}_{\mathrm{PB}}$ : The composition (\%) of the ingredient of each phosphate binder (iron, lanthanum, or sevelamer,) to the ingredients of the whole investigational drug in combination use.

\section{In vivo phosphate-binding capacity Experimental design}

The experiments were conducted at a total of six conditions for each combination of two experiment conditions: $\mathrm{pH}$ of phosphate solution administered ( $\mathrm{pH} 2$ or 7 ) and phosphate binder used in combination with calcium carbonate (PA21, lanthanum carbonate hydrate, or ferric citrate hydrate). The rats were randomly divided into the following five groups for each condition: (1) normal (MC solution + MC solution + distilled water), (2) control (MC solution + MC solution + phosphate solution), (3) calcium carbonate (calcium carbonate $+\mathrm{MC}$ solution + phosphate solution), (4) the other phosphate binder (PA21, lanthanum carbonate hydrate, or ferric citrate hydrate) (MC solution + the other phosphate binder + phosphate solution), (5) combination (calcium carbonate + the other phosphate binder + phosphate solution).

\section{Effect of coadministration of each phosphate binder and calcium carbonate on serum phosphorus level after administration of phosphate solution to rats}

Male SD rats were fasted for approximately $16 \mathrm{~h}$ and then restrained by hand without anesthesia to collect blood samples from the cervical vein $(0 \mathrm{~h}$ measurements). Subsequently, calcium carbonate and other phosphate binders (PA21, lanthanum carbonate hydrate, or ferric citrate hydrate) alone or in combination were orally administered. Furthermore, a $0.5 \% \mathrm{MC}$ solution was orally administered to the normal, control, and single drug-treated animals. Then, phosphate solution $(200 \mathrm{mg} / \mathrm{kg})$ adjusted to $\mathrm{pH} 2$ or 7 was orally administered. The dose of each phosphate binder was set based on the dose [12] at which their suppression of increased serum phosphorus levels in the phosphate solutionloading rat model was confirmed. Blood samples were

Table 1 Content (\%) of ingredients in each phosphate binder

\begin{tabular}{|c|c|c|c|c|c|}
\hline Drug & $\begin{array}{l}\text { PA21 (Sucroferric } \\
\text { oxyhydroxide) }\end{array}$ & $\begin{array}{l}\text { Lanthanum carbonate } \\
\text { hydrate (LC) }\end{array}$ & $\begin{array}{l}\text { Sevelamer } \\
\text { hydrochloride (SH) }\end{array}$ & $\begin{array}{l}\text { Calcium } \\
\text { carbonate (CC) }\end{array}$ & $\begin{array}{l}\text { Ferric citrate } \\
\text { hydrate }(F C)\end{array}$ \\
\hline Ingredient & Iron & Lanthanum & Sevelamer & Calcium & Iron \\
\hline Content of ingredient & $22 \%$ & $52 \%$ & $82 \%^{\mathrm{a}}$ & $40 \%$ & $18 \%$ \\
\hline
\end{tabular}

${ }^{a}$ Calculated using 831.5 as the molecular weight per repeating unit structure, which was calculated using the molecular formula of sevelamer hydrochloride $\left[\left(\mathrm{C}_{3} \mathrm{H}_{7} \mathrm{~N}\right)_{x}\left(\mathrm{C}_{9} \mathrm{H}_{18} \mathrm{ON}_{2}\right)_{y} \cdot \mathrm{nHCl}\right]_{z}$ and the composition ratio of the repeating units of $x=9, y=1, n=4$ 
Table 2 Content (\%) of ingredients and composition (\%) of each ingredient in combination use

\begin{tabular}{|c|c|c|c|c|c|}
\hline \multicolumn{2}{|l|}{ Drugs } & $C C+P A 21$ & $C C+L C$ & $\mathrm{CC}+\mathrm{SH}$ & $C C+F C$ \\
\hline \multicolumn{2}{|l|}{ Ingredient } & Calcium and iron & Calcium and lanthanum & Calcium and sevelamer & Calcium and iron \\
\hline \multicolumn{2}{|l|}{ Content of ingredient $^{a}$} & $31 \%$ & $46 \%$ & $61 \%$ & $29 \%$ \\
\hline \multirow[t]{2}{*}{ Composition of each ingredient ${ }^{\mathrm{b}}$} & $\mathrm{CC}\left(\mathrm{C}_{\mathrm{CC}}\right)$ & $65 \%$ & $43 \%$ & $33 \%$ & $69 \%$ \\
\hline & $\mathrm{PB}\left(\mathrm{C}_{\mathrm{PB}}\right)$ & $35 \%$ & $57 \%$ & $67 \%$ & $31 \%$ \\
\hline
\end{tabular}

${ }^{a}$ Calculated as the percentage of the weight of all the ingredients to that of the investigational drugs. ${ }^{\mathrm{b}} \mathrm{Calculated}$ as the percentage of the weight of CC or PB ingredient to that of all ingredients in investigational drugs. CC Calcium carbonate, LC Lanthanum carbonate hydrate, SH Sevelamer hydrochloride, FC Ferric citrate hydrate, $P B$ Phosphate binder used in combination with calcium carbonate

collected from the cervical vein $1,2,4$, and $6 \mathrm{~h}$ after administration of each investigational drug. The collected blood samples were transferred to Capiject ${ }^{\circ}$ collection tubes (Terumo Corporation, Tokyo, Japan), mixed by inverting, and kept for $30 \mathrm{~min}$ at approximately $23^{\circ} \mathrm{C}$. In a row on end, the level of phosphorus in serum obtained by centrifugation $\left(4{ }^{\circ} \mathrm{C}, 2280 \times g, 10 \mathrm{~min}\right)$ was measured using the Phosphor C-Test Wako and SpectraMax in accordance with the method specified in the previous section. The rats that were used in the experiments were euthanized using the method of inhalation of carbon dioxide $\left(\mathrm{CO}_{2}\right)$.

\section{Analysis}

Each value is shown as the mean alone or \pm standard error. The serum phosphorus level in rats is shown as the change (\%) relative to the $0 \mathrm{~h}$ measurement, which was considered as $100 \%$, and the area under the curve from 0 to $2 \mathrm{~h}\left(\mathrm{AUC}_{0-2} \mathrm{~h}\right)$ was calculated as an evaluation item. The F-test was conducted to analyze differences between the normal and control groups in $\mathrm{AUC}_{0-2 \mathrm{~h}}$ for serum phosphorus level, and Student's $t$-test (for equal variances) and Aspin-Welch's $t$-test (for unequal variances) were conducted. A two-way analysis of variance (ANOVA) was used to analyze the effects of the interaction between each phosphate binder (PA21, lanthanum carbonate hydrate, and ferric citrate hydrate) and calcium carbonate on the serum phosphorus level. Significant differences were identified at $p<0.05$ on a two-tailed basis.

\section{Results}

\section{In vitro phosphate-binding capacity}

\section{Phosphate-binding capacity of each phosphate binder}

The quantities of phosphate adsorbed onto $1 \mathrm{~g}$ of the ingredient of the various phosphate binders at $\mathrm{pH} 2-8$ are shown in Fig. 1. PA21 showed the highest phosphatebinding capacity at $\mathrm{pH} 2$ of all tested $\mathrm{pH}$ levels, and retained relatively high binding capacity at $\mathrm{pH} 3-7$. Lanthanum carbonate hydrate also showed the highest binding capacity at $\mathrm{pH} 2$ of all the tested $\mathrm{pH}$ levels, and relatively high binding capacity at $\mathrm{pH} 5$ and below. However, for lanthanum carbonate hydrate, the binding capacity decreased with increasing $\mathrm{pH}$ above 5 , and phosphate adsorption was hardly observed at $\mathrm{pH} 8$. Sevelamer hydrochloride showed almost the same phosphate-binding capacity at all tested $\mathrm{pH}$ levels. Ferric citrate hydrate showed phosphate-binding capacity at $\mathrm{pH} 2$, but little or no phosphate adsorption was observed at $\mathrm{pH} 3-8$. Calcium carbonate hardly showed any phosphate-binding at $\mathrm{pH} 2$ and exhibited bell-shaped binding, which peaked at $\mathrm{pH} 5$. The $\mathrm{pH}$ values $2 \mathrm{~h}$ after suspension are shown in Table 3. Calcium carbonate increased the $\mathrm{pH}$ of the solution by $\geq 1$ at $\mathrm{pH} 2-5$. Similarly, PA21, lanthanum carbonate hydrate, and sevelamer hydrochloride increased the $\mathrm{pH}$ of the solution at $\mathrm{pH} 3-$ 5 ; however, sevelamer hydrochloride increased the $\mathrm{pH}$ level less than the other two drugs did at $\mathrm{pH} 3-5$. Ferric citrate hydrate decreased the $\mathrm{pH}$ of the solution by $\geq 1$ at pH 5-8.

\section{Phosphate-binding capacity of coadministered calcium carbonate and other phosphate binders}

The comparison of the measured and theoretical quantities of phosphate adsorbed onto $1 \mathrm{~g}$ of the ingredient in combination with each phosphate binder and calcium carbonate at $\mathrm{pH} 2-8$ are shown in Fig. 2. Furthermore, the measured phosphate adsorption quantities of each drug combination are shown in Table 4. The measured values following coadministration of PA21, lanthanum carbonate hydrate, and sevelamer hydrochloride with calcium carbonate were equal to or larger than the theoretical values at all tested $\mathrm{pH}$ levels, except for the combination with sevelamer hydrochloride at $\mathrm{pH} 5$. Therefore, it was suggested that the effects of these combination uses were additive effects or above. In contrast, the measured values following coadministration of ferric citrate hydrate with calcium carbonate were smaller than the theoretical values at all tested $\mathrm{pH}$ levels, suggesting that the effect of this combination was antagonistic. In addition, the phosphate-binding capacities of the combination of PA21, lanthanum carbonate hydrate, and sevelamer hydrochloride with calcium carbonate were stable at $\mathrm{pH} 2-7,2-6$, and $2-8$, respectively. The combination of ferric citrate hydrate with calcium carbonate hardly exhibited any binding capacity at all tested $\mathrm{pH}$ levels. Two hours after suspension, the $\mathrm{pH}$ value increased by $\geq 1$ in the phosphate solution containing 


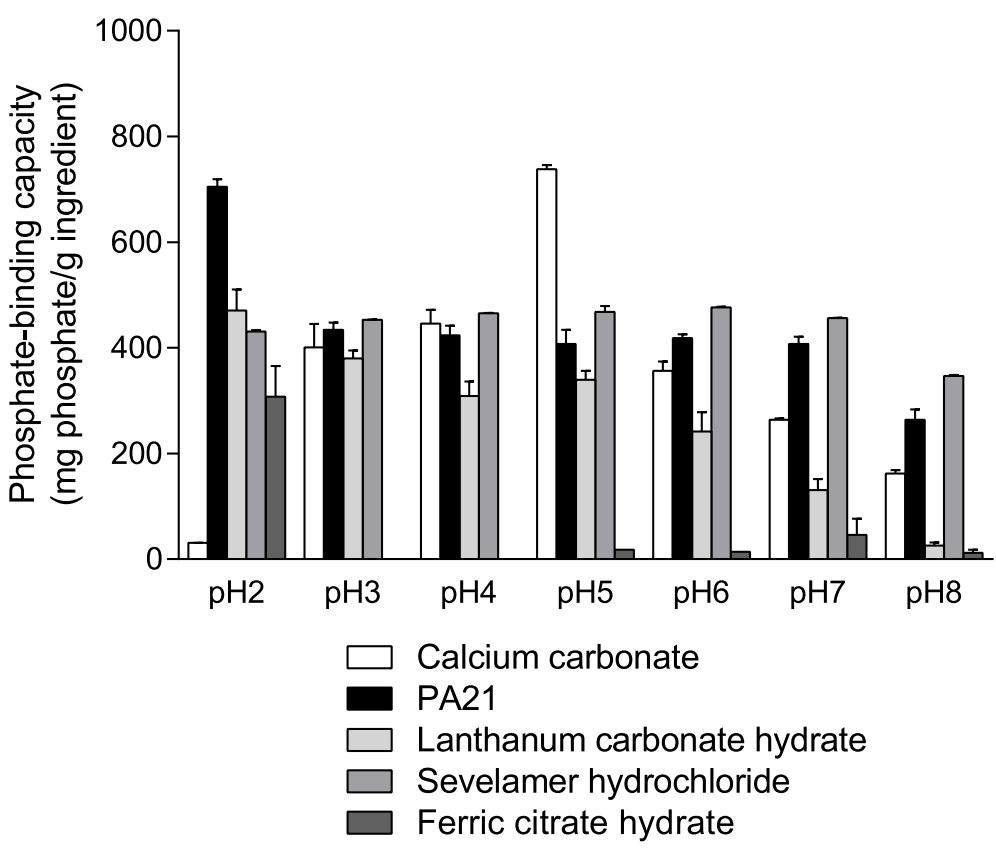

Fig. 1 Phosphate-binding capacity of each phosphate binder. Each column in the figure shows the mean + standard error of three cases (two cases at pH 2 for calcium carbonate, and $\mathrm{ND}$ at pH 3 and 4, one case at pH 5 and 6, and two cases at pH 7 and 8 for ferric citrate hydrate, as no adsorption was observed in any or all cases). The phosphate-binding capacity of each investigational drug was calculated as the quantity of phosphate adsorbed onto $1 \mathrm{~g}$ of phosphate binder ingredient (metal or sevelamer). ND: Not detected

PA21 and lanthanum carbonate hydrate at $\mathrm{pH} 2$, sevelamer hydrochloride at $\mathrm{pH} 2$ and 3, and ferric citrate hydrate at all tested $\mathrm{pH}$ levels in combination with calcium carbonate, compared with that containing each phosphate binder alone (Table 3).

\section{In vivo phosphate-binding capacity}

Effect of coadministration of various phosphate binders and calcium carbonate on serum phosphorus level after administration of phosphate solution to rats

The effects of coadministration of PA21, lanthanum carbonate hydrate, and ferric citrate hydrate with calcium carbonate on temporal transition and $\mathrm{AUC}_{0-2} \mathrm{~h}$ values of serum phosphorus level after the oral administration of phosphate solution $(200 \mathrm{mg} / \mathrm{kg})$ at $\mathrm{pH} 2$ and 7 in rats are shown in Figs 3, 4 and 5, respectively.
Coadministered PA21 $(250 \mathrm{mg} / \mathrm{kg})$ and calcium carbonate $(250 \mathrm{mg} / \mathrm{kg})$ at $\mathrm{pH} 2$ exhibited significant main effects ( $p=0.0131$ and 0.0013 , respectively), and there was no significant interaction $\left(\mathrm{F}_{1,43}=2.2284, p=0.1428\right)$. Similarly, coadministration of PA21 $(400 \mathrm{mg} / \mathrm{kg})$ and calcium carbonate $(500 \mathrm{mg} / \mathrm{kg})$ at $\mathrm{pH} 7$ showed significant main effects $(p=0.0167$ and 0.0343 , respectively), and there was no significant interaction $\left(\mathrm{F}_{1,29}=0.9751, p=0.3316\right)$. Therefore, the combined effects of PA21 and calcium carbonate were additive at both $\mathrm{pH}$ values. Coadministration of lanthanum carbonate hydrate $(125 \mathrm{mg} / \mathrm{kg})$ and calcium carbonate $(250 \mathrm{mg} / \mathrm{kg})$ at $\mathrm{pH} 2$ exhibited significant main effects ( $p=0.0002$ and 0.0001 , respectively) and there was no significant interaction $\left(\mathrm{F}_{1,31}=4.0176, p=0.0538\right)$. Furthermore, coadministration of lanthanum carbonate hydrate $(500 \mathrm{mg} / \mathrm{kg})$ and calcium carbonate $(500 \mathrm{mg} / \mathrm{kg})$ at

Table 3 Last pH after suspension of each phosphate binder and calcium carbonate alone or in combination

\begin{tabular}{llllllllll}
\hline Initial pH of solution & $\mathrm{CC}$ & $\mathrm{PA} 21$ & $\mathrm{LC}$ & $\mathrm{SH}$ & $\mathrm{FC}$ & $\mathrm{CC}+\mathrm{PA2} 2$ & $\mathrm{CC}+\mathrm{LC}$ & $\mathrm{CC}+\mathrm{SH}$ & $\mathrm{CC}+\mathrm{FC}$ \\
\hline 2.0 & 5.3 & 2.3 & 2.3 & 2.2 & 2.1 & 5.6 & 6.3 & 5.7 & 4.4 \\
3.0 & 6.5 & 6.2 & 6.4 & 4.9 & 3.0 & 6.8 & 6.9 & 6.3 & 5.0 \\
4.0 & 6.8 & 6.5 & 6.5 & 5.5 & 3.1 & 6.9 & 7.1 & 6.3 & 5.0 \\
5.0 & 7.3 & 6.6 & 6.7 & 5.7 & 3.1 & 7.0 & 7.2 & 6.3 & 5.0 \\
6.0 & 6.8 & 6.7 & 6.7 & 6.0 & 3.2 & 7.0 & 7.0 & 6.5 & 5.1 \\
7.0 & 7.3 & 7.4 & 7.2 & 7.6 & 3.7 & 7.5 & 7.3 & 7.4 & 5.9 \\
8.0 & 8.7 & 8.9 & 8.1 & 8.5 & 4.2 & 8.9 & 8.7 & 8.6 & 6.7 \\
\hline
\end{tabular}

CC Calcium carbonate, LC Lanthanum carbonate hydrate, SH Sevelamer hydrochloride, FC Ferric citrate hydrate 
a

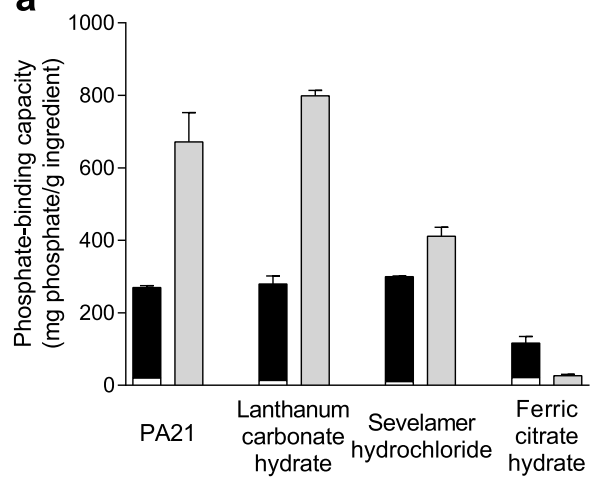

C

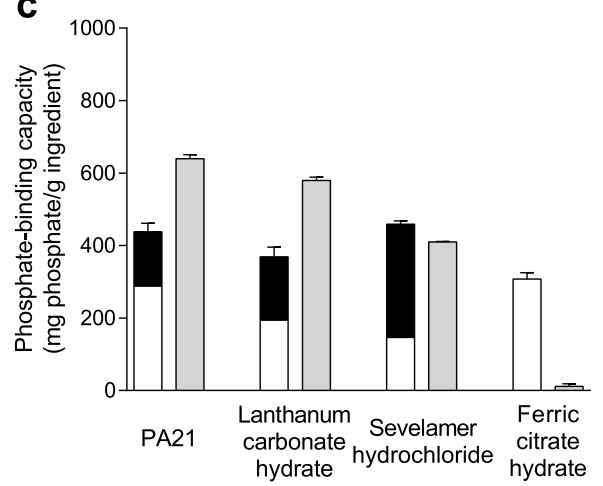

e

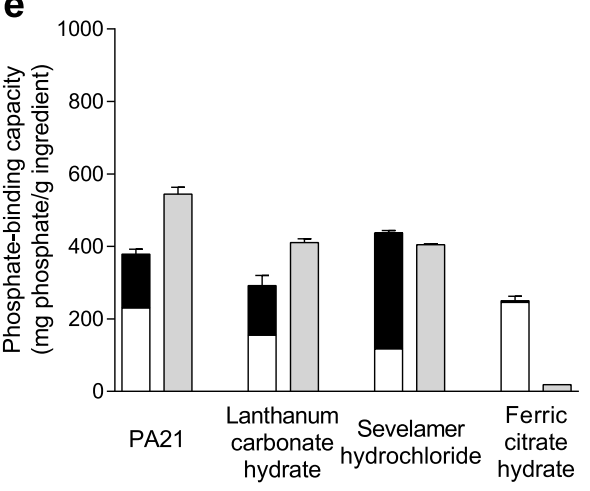

g

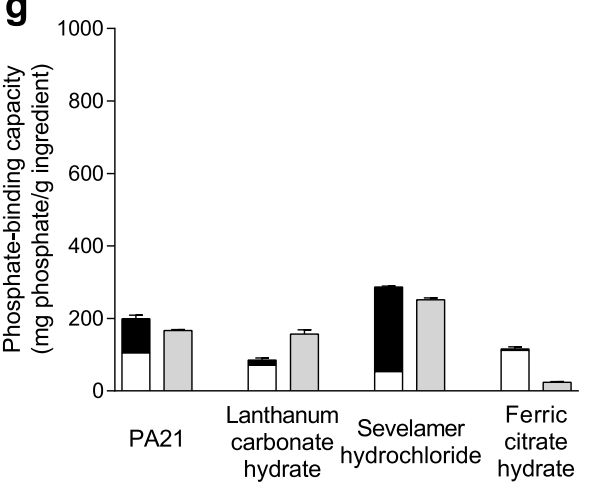

b

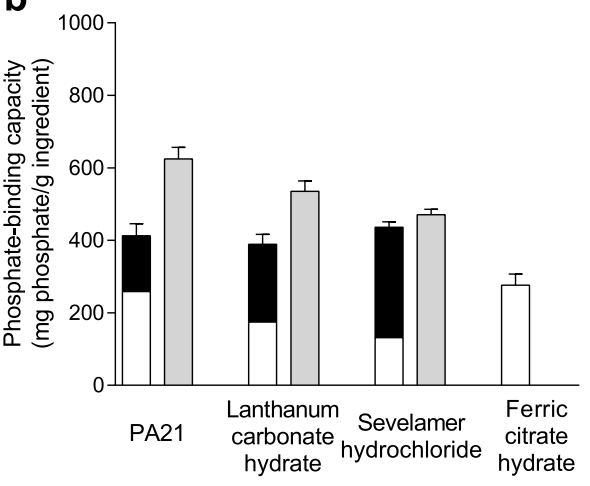

d

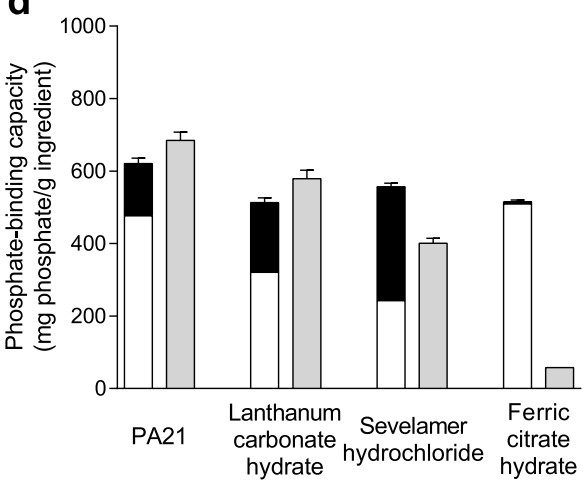

f

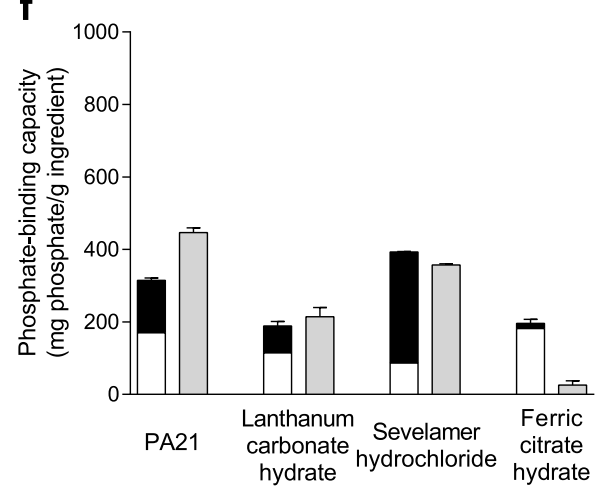

\section{$\square$ Calcium carbonate \\ Each phosphate binder \\ Combination use (Measured value)}

$+\square$ Theoretical value

Fig. 2 Comparison of theoretical and measured phosphate-binding capacity of each coadministration at pH 2-8. The phosphate-binding capacity at (a) $\mathrm{pH}$ 2, (b) pH 3, (c) pH 4, (d) pH 5, (e) pH 6, (f) pH 7, and (g) pH 8. Each column shows the mean + standard error of three cases (two cases for $\mathrm{CC}$ and $\mathrm{CC}+\mathrm{FC}$ at pH 2, ND for FC and CC + FC at pH 3, ND for FC and two case for CC + FC at pH 4, one case for FC and CC + FC at pH 5, one case for $\mathrm{FC}$ and $\mathrm{CC}+\mathrm{FC}$ at pH 6, two cases for $\mathrm{FC}$ at pH 7, and two cases for $\mathrm{FC}$ at pH 8, as no adsorption was observed in any or all cases). ND: Not detected 
Table 4 Measured phosphate-binding capacity of coadministered calcium carbonate and each phosphate binder

\begin{tabular}{lllll}
\hline Drugs & \multicolumn{3}{l}{ Phosphate-binding capacity (mg phosphate/g ingredient) } \\
\cline { 2 - 5 } & CC +PA21 & CC + LC & CC + SH & CC + FC \\
\hline pH 2 & $671 \pm 81$ & $799 \pm 15$ & $411 \pm 25$ & $26 \pm 4$ \\
$\mathrm{pH} 3$ & $625 \pm 32$ & $535 \pm 29$ & $471 \pm 15$ & ND \\
$\mathrm{pH} 4$ & $640 \pm 11$ & $579 \pm 10$ & $410 \pm 1$ & $11 \pm 7$ \\
$\mathrm{pH} 5$ & $684 \pm 23$ & $579 \pm 24$ & $401 \pm 14$ & 58 \\
$\mathrm{pH} 6$ & $544 \pm 19$ & $410 \pm 11$ & $405 \pm 3$ & 19 \\
$\mathrm{pH} 7$ & $446 \pm 13$ & $214 \pm 25$ & $357 \pm 4$ & $26 \pm 12$ \\
$\mathrm{pH} 8$ & $167 \pm 3$ & $157 \pm 11$ & $251 \pm 6$ & $24 \pm 2$
\end{tabular}

Each value shows the mean value \pm standard error of three cases (two cases for $\mathrm{CC}+\mathrm{FC}$ at $\mathrm{pH}$ 2, ND for $\mathrm{CC}+\mathrm{FC}$ at pH 3, two cases for $\mathrm{CC}+\mathrm{FC}$ at pH 4, one case for $\mathrm{CC}+\mathrm{FC}$ at $\mathrm{pH} 5$, and one case for $\mathrm{CC}+\mathrm{FC}$ at $\mathrm{pH} 6$ as no adsorption was observed in any or all cases). CC Calcium carbonate, LC Lanthanum carbonate hydrate, SH Sevelamer hydrochloride, FC Ferric citrate hydrate, ND Not detected

$\mathrm{pH} 7$ showed significant main effects $(p=0.0262$ and 0.0223 , respectively), and there was a significant interaction $\left(\mathrm{F}_{1,41}=12.0618, p=0.0012\right)$. Therefore, the combined effects of lanthanum carbonate hydrate and calcium carbonate were additive at $\mathrm{pH} 2$ and antagonistic at $\mathrm{pH} 7$. Coadministration of ferric citrate hydrate $(500 \mathrm{mg} / \mathrm{kg})$ and calcium carbonate $(250 \mathrm{mg} / \mathrm{kg})$ at $\mathrm{pH} 2$ showed significant main effects $(p=0.0061$ and 0.0011 , respectively), and there was a significant interaction $\left(\mathrm{F}_{1,38}=22.2665, p<\right.$ $0.001)$. In contrast, calcium carbonate $(500 \mathrm{mg} / \mathrm{kg})$ showed a significant main effect $(p=0.0012)$ at $\mathrm{pH} 7$ following coadministration with ferric citrate hydrate; however, no significant main effect of ferric citrate hydrate was observed at the high dose of $1000 \mathrm{mg} / \mathrm{kg}(p=0.5341)$. Therefore, the combined effect of ferric citrate hydrate and calcium carbonate were antagonistic at $\mathrm{pH} 2$ and were not evaluated at $\mathrm{pH} 7$ because no significant main effect of ferric citrate hydrate was observed.

\section{Discussion}

Hyperphosphatemia is one of the important risk factors which affecting mortality in dialysis patients $[3,17]$. The control of serum phosphorus level is performed as treatment of hyperphosphatemia, through dietary phosphate restriction, dialysis, and oral administration of phosphate binders, and especially phosphate binders play a major role in the control of serum phosphorus levels $[18,19]$. Various drugs are used as phosphate binders, and each drug has its own advantages, disadvantages, and adverse effects [19-21]. Adverse effects are usually associated with the administration of high-doses of phosphate binders; therefore, combination therapy is considered to contribute towards reducing these adverse effects and costs [7]. In clinical practice, it has been reported that a little under $30 \%$ of patients on dialysis received some kind of combination therapy for their phosphate binder prescription [22]. Especially, combination of calciumbased phosphate binders is estimated to be approximately $20 \%$ at minimum [23] and is the most common prescribing pattern in combination therapy. In Japan, calcium carbonate is the only approved calcium-based phosphate binder; therefore, it is considered that the majority of combination therapy prescriptions are combinations of calcium carbonate and other phosphate binders.

We examined the phosphate-binding capacity of combinations of calcium carbonate and other phosphate binders using in vitro studies, and the results indicated that some combination do not demonstrate the expected phosphate-binding capacity (theoretical phosphatebinding capacity; sum of efficacy of two binders). Among the combinations examined, the measured capacities of the combination of calcium carbonate with PA21 and lanthanum carbonate hydrate at $\mathrm{pH} 2$ were approximately twice as high as the theoretical values. Regarding PA21, the rational reason was considered to be that, when calcium carbonate was coadministered with PA21, the phosphate-binding capacity of calcium carbonate was enhanced as the $\mathrm{pH}$ of the solution approached the $\mathrm{pH}$ at which calcium carbonate has the greatest efficacy. Moreover, the phosphate bound to PA21 at an acidic $\mathrm{pH}$ was retained even when the $\mathrm{pH}$ increased [24], which might also apply to lanthanum carbonate hydrate. Furthermore, enhancement of the phosphate-binding capacity differed between PA21 and sevelamer hydrochloride in combination with calcium carbonate, although the $\mathrm{pH}$ values were the same. This might be because the changes in $\mathrm{pH}$ immediately after suspension differed. The measured binding capacity of the combination of calcium carbonate with ferric citrate hydrate was lower than the theoretical value possibly because citrate ions chelate and decrease calcium ions, which can adsorb phosphate ions, and the $\mathrm{pH}$ at which the ferric citrate hydrate exerts phosphate-binding capacity was not maintained as coadministration with calcium carbonate increased the $\mathrm{pH}$ of the solution. Regarding the effect of $\mathrm{pH}$ on the phosphate-binding capacity of each combination except for that with ferric citrate hydrate, the phosphate-binding capacity of coadministered calcium carbonate and lanthanum carbonate hydrate at $\mathrm{pH}$ 7 and 8 and PA21 at pH 8 was less than half the values at $\mathrm{pH} 2-5$. The phosphate-binding capacity of the coadministered calcium carbonate and sevelamer hydrochloride was the lowest at $\mathrm{pH} 8$ of all tested $\mathrm{pH}$ conditions; however, even at $\mathrm{pH} 8$, the capacity was approximately $50 \%$ of that at $\mathrm{pH} 2-5$. This indicates that the phosphate-binding capacity following coadministration of calcium carbonate with sevelamer hydrochloride, PA21, and lanthanum carbonate hydrate was not affected by $\mathrm{pH}$ conditions in this order. This result was consistent with the insensitivity of the phosphate- 

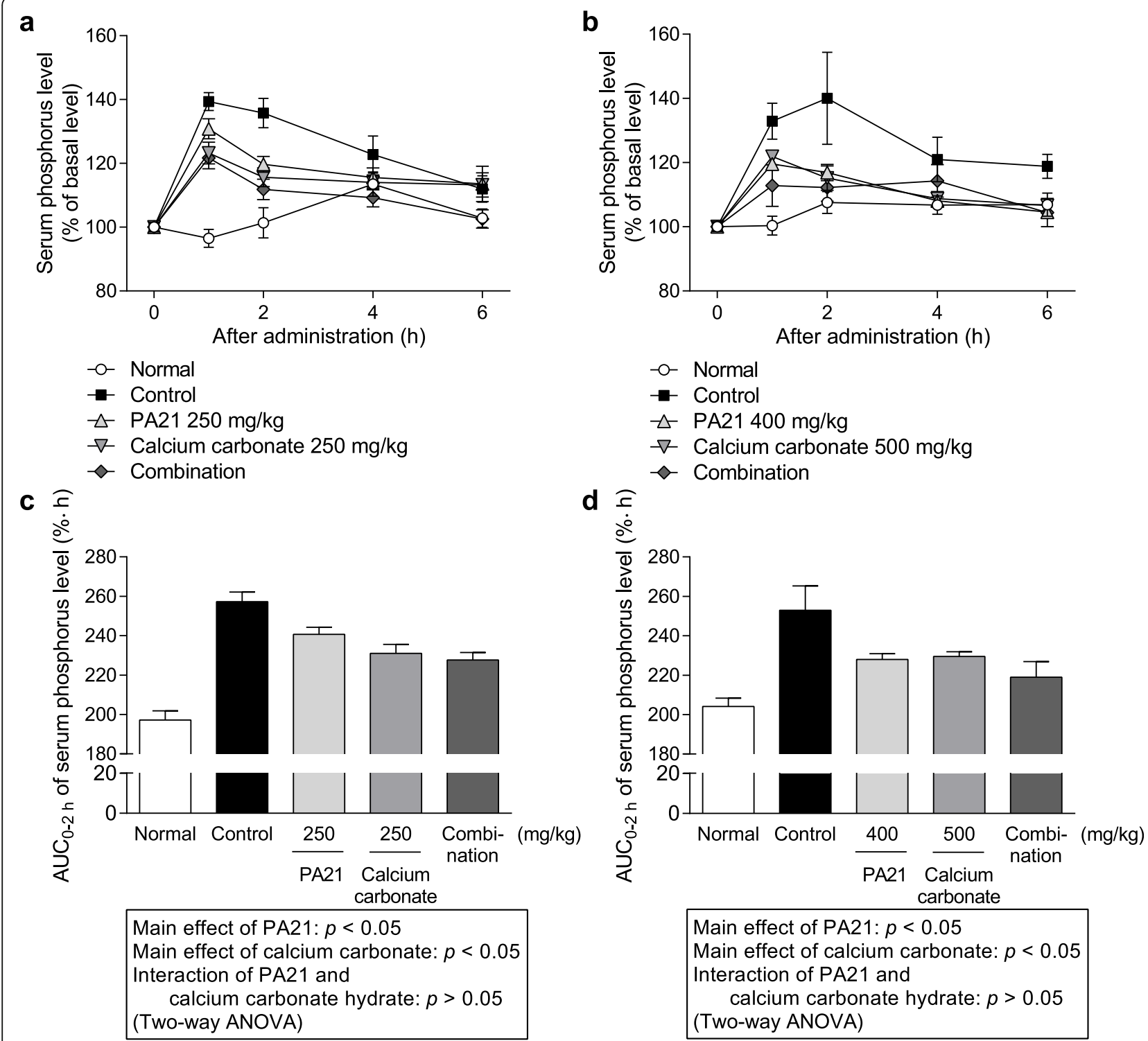

Fig. 3 Serum phosphorus level following coadministration of PA21 and calcium carbonate. Temporal transition at (a) pH 2 and (b) pH 7. Area under the curve from 0 to $2 \mathrm{~h}\left(\mathrm{AUC}_{0-2 \mathrm{~h}}\right.$ ) of serum phosphorus level at (c) $\mathrm{pH} 2$ and (d) $\mathrm{pH}$ 7. Each dot shows the mean value \pm standard error, and each column shows the mean value + standard error of 7-12 cases at pH 2 (7 cases for normal, 11 cases for control, 12 cases for PA21, 11 cases for calcium carbonate, and 11 cases for combination) and 7-10 cases at pH 7 (10 cases for normal, 8 cases for control, 10 cases for PA21, 8 cases for calcium carbonate, and 7 cases for combination)

binding capacity to $\mathrm{pH}$ with single use of phosphate binders [12].

The efficacy of coadministered calcium carbonate and each phosphate binder at $\mathrm{pH} 2$ and 7 was investigated using the phosphate solution loading model previously reported as an in vivo evaluation system [12]. Although $\mathrm{pH} 2$ is lower than the $\mathrm{pH}$ conditions in the stomach [16], since the phosphate-binding capacities of ferric citrate hydrate was severely diminished at $\mathrm{pH} \geq 3$ in the in vitro study, this $\mathrm{pH}$ was set so that ferric citrate hydrate could exert its efficacy. We used $\mathrm{pH} 7$ to simulate the $\mathrm{pH}$ conditions of the upper and middle intestine, which is the main site of Na-independent inorganic phosphate absorption [25, 26]. Referring to our previous study [12], the doses of phosphate binders were set as the doses at which the main effects of each factor were observed using a two-way ANOVA to analyze the $\mathrm{AUC}_{0-2 \mathrm{~h}}$ of serum phosphorus level. However, at $\mathrm{pH}$, ferric citrate hydrate was examined at the dosage at which the main effects were not observed, because this drug did not suppress the increased serum phosphorus level even at a high dose of $1000 \mathrm{mg} / \mathrm{kg}$ and a higher dose was considered unreasonable. The result of the two-way ANOVA indicated that the combined effect of 

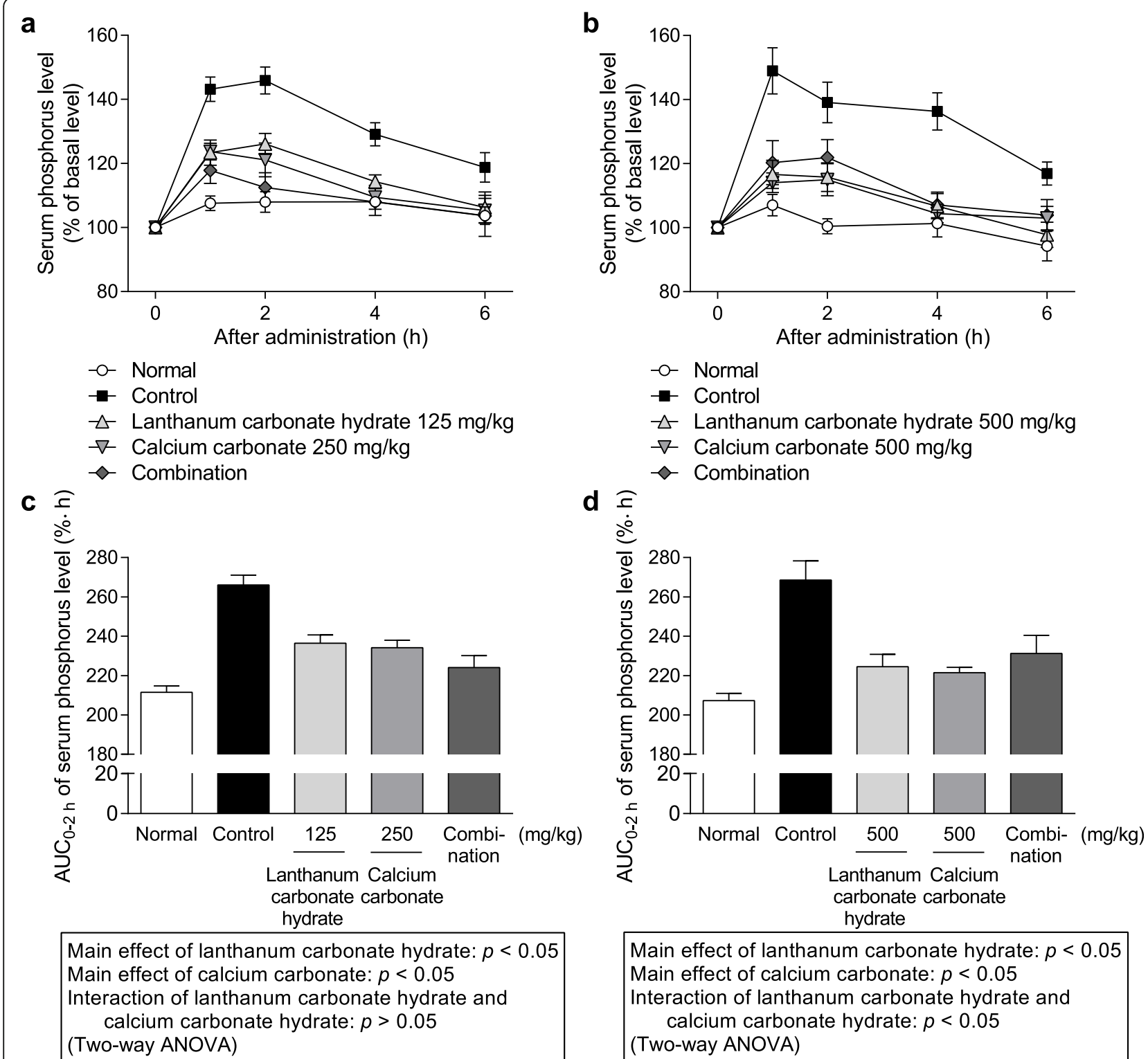

Main effect of lanthanum carbonate hydrate: $p<0.05$
Main effect of calcium carbonate: $p<0.05$
Interaction of lanthanum carbonate hydrate and
calcium carbonate hydrate: $p<0.05$
(Two-way ANOVA)

Fig. 4 Serum phosphorus level following coadministration of lanthanum carbonate hydrate and calcium carbonate. Temporal transition at (a) pH 2 and (b) $\mathrm{pH} 7$. Area under the curve from 0 to $2 \mathrm{~h}\left(\mathrm{AUC}_{0-2} \mathrm{~h}\right.$ ) of serum phosphorus level at (c) $\mathrm{pH} 2$ and (d) $\mathrm{pH} 7$. Each dot shows the mean value \pm standard error, and each column shows the mean value + standard error of 8-12 cases at pH 2 (12 cases for normal, 10 cases for control, 9 cases for lanthanum carbonate hydrate, 8 cases for calcium carbonate, and 8 cases for combination) and 10-12 cases at pH 7 (12 cases for normal, 11 cases for control, 12 cases for lanthanum carbonate hydrate, 10 cases for calcium carbonate, and 12 cases for combination)

calcium carbonate with PA21 at both $\mathrm{pH}$ values and with lanthanum carbonate hydrate at $\mathrm{pH} 2$ were additive, and the combined effect of calcium carbonate with lanthanum carbonate hydrate at $\mathrm{pH} 7$ and with ferric citrate hydrate at $\mathrm{pH} 2$ were antagonistic. It is not clear why coadministered lanthanum carbonate hydrate and calcium carbonate did not show efficacy at $\mathrm{pH} 7$. However, coadministration of lanthanum carbonate hydrate and calcium carbonate might create carbonate species-rich conditions, resulting in the reduced solubility of calcium carbonate and inhibition of the phosphate-binding capacity of calcium carbonate. This notion is based on reports that the solubility of calcium carbonate declines under carbonate species-rich conditions at pH 7.5 [27]. Therefore, examination of the coadministration of calcium carbonate and each phosphate binder showed that the result of the in vitro study mostly reflected that of the in vivo study, except with coadministration of calcium carbonate and lanthanum carbonate hydrate at $\mathrm{pH}$ 7. Furthermore, the combined effect of PA21 and calcium carbonate was retained even at changing $\mathrm{pH}$ condition in vivo $[16,28,29]$. 


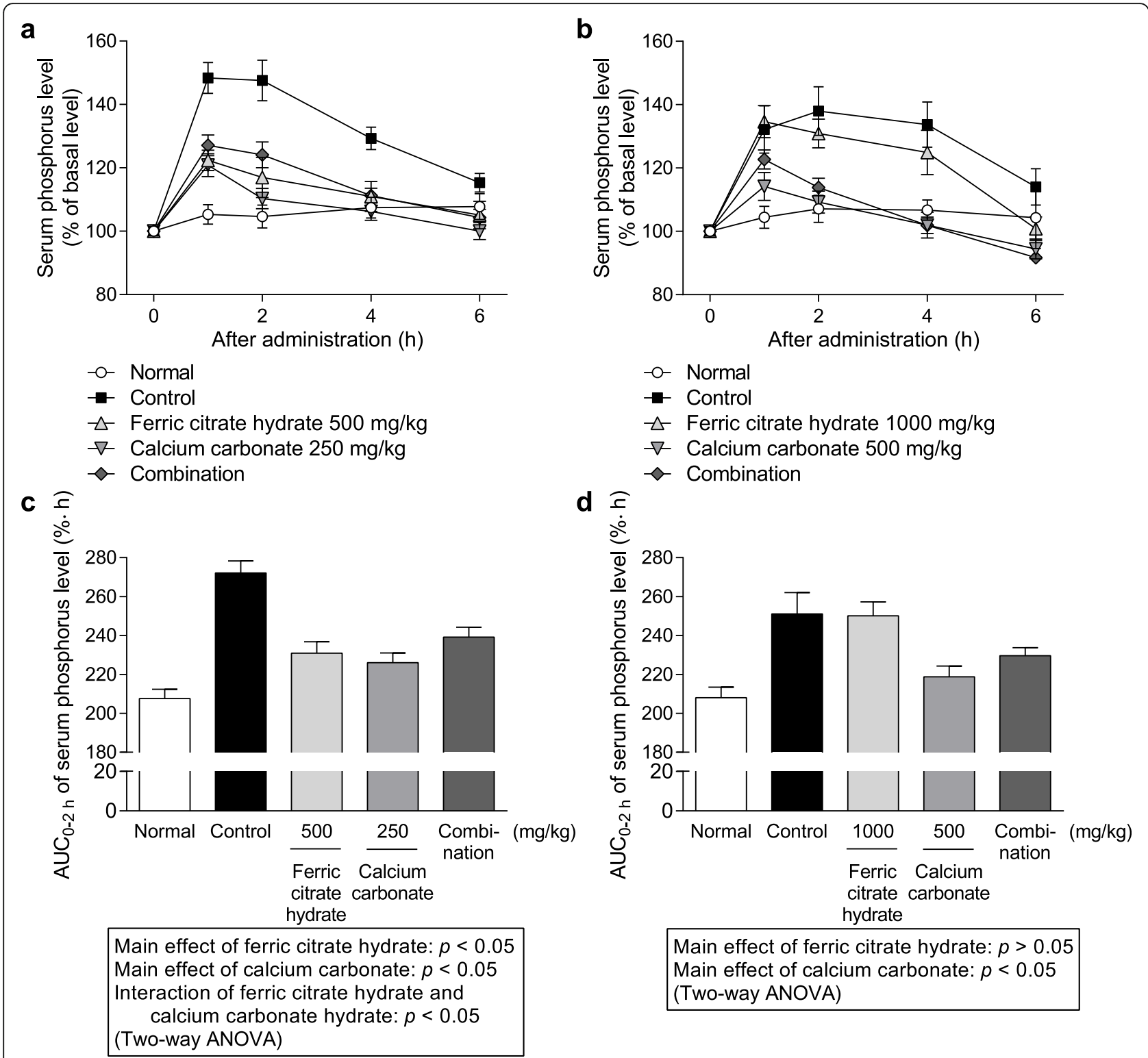

Fig. 5 Serum phosphorus level following coadministration of ferric citrate hydrate and calcium carbonate. Temporal transition at (a) pH 2 and (b) $\mathrm{pH}$ 7. Area under the curve from 0 to $2 \mathrm{~h}\left(\mathrm{AUC}_{0-2} \mathrm{~h}\right.$ ) of serum phosphorus level at (c) $\mathrm{pH} 2$ and (d) $\mathrm{pH}$ 7. Each dot shows the mean value \pm standard error, and each column shows the mean value + standard error of 9-12 cases at pH 2 (11 cases for normal, 12 cases for control, 11 cases for ferric citrate hydrate, 10 cases for calcium carbonate, and 9 cases for combination) and 9-12 cases at pH 7 (11 cases for normal, 10 cases for control, 12 cases for ferric citrate hydrate, 9 cases for calcium carbonate, and 11 cases for combination)

It is not clear why the efficacy of coadministered lanthanum carbonate hydrate and calcium carbonate at $\mathrm{pH}$ 7 in the in vivo study differ from that in the in vitro study; however, there is a possibility that the change in $\mathrm{pH}$ affected the phosphate-binding capacity, resulting in unforeseen consequences, since the $\mathrm{pH}$ changed in the transition from the stomach to intestine in the in vivo study. Furthermore, phosphate administered in solution is absorbed relatively quickly into the body [30], whereas calcium carbonate and lanthanum carbonate hydrate are considered to have a slower rate of phosphate adsorption than PA21 [13]. Therefore, there is also the possibility that phosphate was absorbed into the body before the binders adsorbed phosphate and, consequently, lanthanum carbonate hydrate and calcium carbonate were not efficacious. The above observations suggest that the efficacy of phosphate binders might be limited under the conditions used in this study where phosphate loading by solution may cause more rapid changes in $\mathrm{pH}$ and quicker absorption of phosphate into the body than those occurring clinically. However, the combined effect of PA21 and calcium carbonate was stable even in this 
study and, thus, a stable combined effect can be expected to also be exerted in clinical settings, wherein the conditions would be more suitable for phosphate binders.

Gastric secretory inhibitors such as proton pump inhibitors and histamine H2-receptor antagonists are known to affect the gastrointestinal $\mathrm{pH}$ and are used to treat peptic ulcer and gastroesophageal reflux disease and eradicate Helicobacter pylori. It has been reported that the key to successful treatment is to maintain the intragastric $\mathrm{pH}$ at $\geq 3, \geq 4$, and at the neutral conditions, during each treatment [31-33], and these drugs are considered to increase the intragastric $\mathrm{pH}$ to these levels [34-36]. These drugs have been reported to be prescribed to approximately $38 \%$ of hemodialysis patients [37]; therefore, considerable number of patients are presumed to use gastric secretory inhibitors with phosphate binders. Moreover, the serum phosphorus lowering effect of calcium carbonate has been reported to be attenuated by administering these drugs [38, 39]. The same phenomenon has not yet been reported with other phosphate binders and there is a possibility that gastric secretory inhibitors attenuate their efficacy. However, in this study, PA21 exhibited a stable phosphate-binding capacity that was unsusceptible to $\mathrm{pH}$ both as a singledrug and in combination with calcium carbonate. This indicates that PA21 may control serum phosphorus levels adequately even when coadministered with prescribed gastric secretory inhibitors, which is an interesting consideration.

\section{Conclusion}

In this experimental study, sevelamer hydrochloride, PA21, and lanthanum carbonate hydrate exhibited efficacy that was equal to or greater than the theoretical efficacy when coadministered with calcium carbonate. Furthermore, the efficacy of these drugs was shown to be insensitive to $\mathrm{pH}$ and adequately retained as both single-drug treatments or coadministered with calcium carbonate, in this order. In contrast, the combination of ferric citrate hydrate and calcium carbonate hardly showed any efficacy regardless of $\mathrm{pH}$ conditions. These results suggest that PA21 exhibited good and stable efficacy in combination with calcium carbonate at the

Table 5 Combined effect expected in clinical practice

\begin{tabular}{lll}
\hline Drugs & $\begin{array}{l}\mathrm{pH} 2 \\
\text { (Normal condition) }\end{array}$ & $\begin{array}{l}\mathrm{pH7} \\
\text { (Condition simulating } \\
\text { increased gastrointestinal pH) }\end{array}$ \\
\hline $\mathrm{CC}+\mathrm{PA} 21$ & $\uparrow$ & $\uparrow$ \\
$\mathrm{CC}+\mathrm{LC}$ & $\uparrow$ & $\downarrow$ \\
$\mathrm{CC}+\mathrm{FC}$ & $\downarrow$ & - \\
\hline $\mathrm{CC}$ Calcium carbonate, $\mathrm{LC}$ Lanthanum carbonate hydrate, $F C$ Ferric citrate \\
hydrate. $\uparrow:$ Additive effect, $\downarrow$ : Antagonistic effect, - : The combined effect was \\
not evaluated because the main effect of ferric citrate hydrate was \\
not observed
\end{tabular}

gastrointestinal $\mathrm{pH}$ range and can be expected to show stable efficacy with changes in $\mathrm{pH}$ conditions of the gastrointestinal tract induced by other drugs. However, it is possible that lanthanum carbonate hydrate and ferric citrate hydrate in combination with calcium carbonate cannot exhibit the expected efficacy under certain $\mathrm{pH}$ conditions (Table 5).

\section{Abbreviations}

ANOVA: Analysis of variance; $\mathrm{AUC}_{0-2} \mathrm{~h}$ : Area under the curve from 0 to $2 \mathrm{~h}$; CKD: Chronic kidney disease; CKD-MBD: Chronic kidney disease-mineral and bone disorder; MC: Methylcellulose; SD: Sprague-Dawley

\section{Acknowledgments}

Not applicable.

\section{Authors' contributions}

AY conceptualized the study, designed and performed the in vivo study, analyzed and interpreted the data, and wrote the manuscript. KA designed and performed the in vivo study, analyzed and interpreted the data regarding the in vivo study. KT designed and performed the in vitro study, analyzed and interpreted the data regarding the in vitro study. SY1 conceptualized, designed and performed the in vitro study, and acquired the data regarding the in vitro study. SY2 and YT performed the in vivo study. ST conceptualized the study, helped with the laboratory work as supervisor and revised the manuscript. HT helped with the laboratory work as supervisor and revised the manuscript. All authors read and approved the final manuscript.

\section{Funding}

This study and writing assistance for this manuscript were funded by Kissei Pharmaceutical Co., Ltd. All authors are employees of Kissei Pharmaceutical Co., Ltd.

\section{Availability of data and materials}

All data generated or analysed during this study are included in this published article.

\section{Ethics approval and consent to participate}

This study was approved by the Animal Care and Use Committee of Central Research Laboratories in Kissei Pharmaceutical Co., Ltd., which conforms to the current Japanese law (Committee reference No. 16A-045 and 16B-024).

\section{Consent for publication}

Not applicable.

\section{Competing interests}

This study was funded by Kissei Pharmaceutical Co., Ltd., where AY, KA, KT, SY1, SY2, YT, ST and HT are employees. This does not alter the authors' adherence to all the BMC Nephrology policies on sharing data and materials, as detailed online in the guide for authors.

Received: 13 September 2019 Accepted: 3 December 2019 Published online: 12 December 2019

\section{References}

1. Ketteler M, Wüthrich RP, Floege J. Management of hyperphosphataemia in chronic kidney disease-challenges and solutions. Clin Kidney J. 2013;6:128-36.

2. Covic A, Rastogi A. Hyperphosphatemia in patients with ESRD: assessing the current evidence linking outcomes with treatment adherence. BMC Nephrol. 2013;14:153.

3. Friedman EA. Consequences and management of hyperphosphatemia in patients with renal insufficiency. Kidney Int. 2005;67(Suppl 95):S1-7.

4. Moe S, Drüeke T, Cunningham J, Goodman W, Martin K, Olgaard K, et al. Kidney disease: improving global outcomes (KDIGO). Definition, evaluation, and classification of renal osteodystrophy: a position statement from kidney disease: improving global outcomes (KDIGO). Kidney Int. 2006;69:1945-53.

5. Taniguchi M, Fukagawa M, Fujii N, Hamano T, Shoji T, Yokoyama K, et al. Committee of Renal Data Registry of the Japanese Society for Dialysis 
Therapy. Serum phosphate and calcium should be primarily and consistently controlled in prevalent hemodialysis patients. Ther Apher Dial. 2013;17:221-8.

6. Fukagawa M, Yokoyama K, Koiwa F, Taniguchi M, Shoji T, Kazama JJ, et al. CKD-MBD guideline working group; Japanese Society for Dialysis Therapy. Clinical practice guideline for the management of chronic kidney diseasemineral and bone disorder. Ther Apher Dial. 2013;17:247-88.

7. Locatelli F, Del Vecchio L, Violo L, Pontoriero G. Phosphate binders for the treatment of hyperphosphatemia in chronic kidney disease patients on dialysis: a comparison of safety profiles. Expert Opin Drug Saf. 2014;13:551-61.

8. Koiwa F, Yokoyama K, Fukagawa M, Akizawa T. Efficacy and safety of Sucroferric Oxyhydroxide and calcium carbonate in hemodialysis patients. Kidney Int Rep. 2018;3:185-92.

9. Ouellet G, Cardinal H, Mailhot M, Ste-Marie LG, Roy L. Does concomitant administration of sevelamer and calcium carbonate modify the control of phosphatemia? Ther Apher Dial. 2010;14:172-7.

10. Guérin AP, London GM, Marchais SJ, Metivier F. Arterial stiffening and vascular calcifications in end-stage renal disease. Nephrol Dial Transplant. 2000;15:1014-21.

11. Block GA, Raggi P, Bellasi A, Kooienga L, Spiegel DM. Mortality effect of coronary calcification and phosphate binder choice in incident hemodialysis patients. Kidney Int. 2007;71:438-41.

12. Yaguchi A, Yonekubo S, Maruyama I, Tatemichi S, Maruyama K, Kobayashi M. Comparison of phosphate binding capacities of PA21, a novel phosphate binder, with those of other phosphate binders in vitro and in vivo. Drug Res. 2016;66:262-9.

13. Schumacher SP, Schurgers $\sqcup$, Vervloet MG, Neradova A. Influence of $\mathrm{pH}$ and phosphate concentration on the phosphate binding capacity of five contemporary binders. An in vitro study. Nephrology (Carlton). 2019;24:221-6.

14. Ishii T, Nakajima Y, Oyama K. Comparative analysis of the phosphatebinding effects of sucroferric oxyhydroxide, ferric citrate, and lanthanum carbonate. Ren Replace Ther. 2017:3:38.

15. Cannata-Andía JB, Fernández-Martín JL, Locatelli F, London G, Gorriz JL, Floege J, et al. Use of phosphate-binding agents is associated with a lower risk of mortality. Kidney Int. 2013;84:998-1008.

16. Shiga A, Sasaki T, Horii N. Correlations among pH and mg, $\mathrm{Ca}, \mathrm{P}, \mathrm{Na}, \mathrm{K}, \mathrm{Cl}^{-}$ and $\mathrm{HCO}_{3}{ }^{-}$contents of digesta in the gastro-intestinal tract of rats. Jpn J Vet Sci. 1987:49:973-9.

17. Abe M, Okada K, Soma M. Mineral metabolic abnormalities and mortality in dialysis patients. Nutrients. 2013;5:1002-23.

18. Amiri FS. Contemporary management of phosphorus retention in chronic kidney disease: a review. Clin Exp Nephrol. 2015;19:985-99.

19. Ketteler M, Liangos O, Biggar PH. Treating hyperphosphatemia - current and advancing drugs. Expert Opin Pharmacother. 2016:17:1873-9.

20. Tonelli M, Pannu N, Manns B. Oral phosphate binders in patients with kidney failure. N Engl J Med. 2010;362:1312-24.

21. Gutekunst L. An update on phosphate binders: a Dietitian's perspective. J Ren Nutr. 2016;26:209-18.

22. Fissell RB, Karaboyas A, Bieber BA, Sen A, Li Y, Lopes AA, et al. Phosphate binder pill burden, patient-reported non-adherence, and mineral bone disorder markers: findings from the DOPPS. Hemodial Int. 2016;20:38-49.

23. Lopes AA, Tong L, Thumma J, Li Y, Fuller DS, Morgenstern H, et al. Phosphate binder use and mortality among hemodialysis patients in the Dialysis outcomes and practice patterns study (DOPPS): evaluation of possible confounding by nutritional status. Am J Kidney Dis. 2012;60:90-101.

24. Wilhelm M, Gaillard S, Rakov V, Funk F. The iron-based phosphate binder PA21 has potent phosphate binding capacity and minimal iron release across a physiological pH range in vitro. Clin Nephrol. 2014;81:251-8.

25. Giral H, Caldas Y, Sutherland E, Wilson P, Breusegem S, Barry N, et al. Regulation of rat intestinal $\mathrm{Na}$-dependent phosphate transporters by dietary phosphate. Am J Physiol Renal Physiol. 2009;297:F1466-75.

26. Marks J, Lee GJ, Nadaraja SP, Debnam ES, Unwin RJ. Experimental and regional variations in $\mathrm{Na}^{+}$-dependent and $\mathrm{Na}^{+}$-independent phosphate transport along the rat small intestine and colon. Physiol Rep. 2015;3:e12281.

27. Goss SL, Lemons KA, Kerstetter JE, Bogner RH. Determination of calcium salt solubility with changes in $\mathrm{pH}$ and $\mathrm{P}_{\mathrm{CO} 2}$, simulating varying gastrointestinal environments. J Pharm Pharmacol. 2007;59:1485-92.

28. Maurer JM, Schellekens RC, van Rieke HM, Wanke C, lordanov V, Stellaard F, et al. Gastrointestinal pH and transit time profiling in healthy volunteers using the IntelliCap system confirms lleo-colonic release of ColoPulse tablets. PLoS One. 2015;10:e0129076.
29. Nugent SG, Kumar D, Rampton DS, Evans DF. Intestinal luminal pH in inflammatory bowel disease: possible determinants and implications for therapy with aminosalicylates and other drugs. Gut. 2001;48:571-7.

30. Kayne LH, D'Argenio DZ, Meyer JH, Hu MS, Jamgotchian N, Lee DB. Analysis of segmental phosphate absorption in intact rats. A compartmental analysis approach. J Clin Invest. 1993;91:915-22.

31. Hunt RH, Cederberg C, Dent J, Halter F, Howden C, Marks IN, et al. Optimizing acid suppression for treatment of acid-related diseases. Dig Dis Sci. 1995;40(Suppl):24S-49S.

32. Hunt RH. Importance of pH control in the management of GERD. Arch Intern Med. 1999;159:649-57.

33. Sachs G, Shin JM, Munson K, Vagin O, Lambrecht N, Scott DR, et al. Review article: the control of gastric acid and helicobacter pylori eradication. Aliment Pharmacol Ther. 2000;14:1383-401.

34. Kirchheiner J, Glatt S, Fuhr U, Klotz U, Meineke I, Seufferlein T, et al. Relative potency of proton-pump inhibitors-comparison of effects on intragastric pH. Eur J Clin Pharmacol. 2009;65:19-31.

35. Hedenström H, Alm C, Kraft M, Grahnén A. Intragastric pH after oral administration of single doses of ranitidine effervescent tablets, omeprazole capsules and famotidine fast-dissolving tablets to fasting healthy volunteers. Aliment Pharmacol Ther. 1997;11:1137-41.

36. Fujisawa T, Adachi K, Komazawa Y, Mihara T, Azumi T, Katsube T, et al. Helicobacter pylori infection prevents the occurrence of the tolerance phenomenon of histamine $\mathrm{H} 2$ receptor antagonists. Aliment Pharmacol Ther. 2004;20:559-65.

37. Bailie GR, Mason NA, Elder SJ, Andreucci VE, Greenwood RN, Akiba T, et al. Large variations in prescriptions of gastrointestinal medications in hemodialysis patients on three continents: the Dialysis outcomes and practice patterns study (DOPPS). Hemodial Int. 2006;10:180-8.

38. Matsunaga C, Izumi S, Furukubo T, Satoh M, Yamakawa T, Uchida T, et al. Effect of famotidine and lansoprazole on serum phosphorus levels in hemodialysis patients on calcium carbonate therapy. Clin Nephrol. 2007;68:93-8.

39. Tatsuzawa M, Ogawa R, Ohkubo A, Shimojima K, Maeda K, Echizen H, et al. Influence of proton pump inhibitors and histamine $\mathrm{H}_{2}$ receptor antagonists on serum phosphorus level control by calcium carbonate in patients undergoing hemodialysis: a retrospective medical chart review. J Pharm Health Care Sci. 2016;2:34

\section{Publisher's Note}

Springer Nature remains neutral with regard to jurisdictional claims in published maps and institutional affiliations.

Ready to submit your research? Choose BMC and benefit from:

- fast, convenient online submission

- thorough peer review by experienced researchers in your field

- rapid publication on acceptance

- support for research data, including large and complex data types

- gold Open Access which fosters wider collaboration and increased citations

- maximum visibility for your research: over $100 \mathrm{M}$ website views per year

At $\mathrm{BMC}$, research is always in progress.

Learn more biomedcentral.com/submission 